\title{
Environmental Protection Technologies as an Aspect of Research into Critical Infrastructures
}

\author{
Elena P. Maysyuk ${ }^{1}$, Irina Yu. Ivanova ${ }^{2}$ \\ Melentiev Energy Systems Institute of Siberian Branch of the Russian Academy of Sciences, \\ Lermontov str., 130 \\ Irkutsk, Russia \\ ${ }^{1}$ E-mail: maysyuk@isem.irk.ru \\ ${ }^{2}$ E-mail: nord@isem.irk.ru
}

\begin{abstract}
Environmental protection technologies are an important link in the energy sector. They provide environmental safety and are in demand in regions especially with significant volumes of coal combustion. The studying of the interdependence of energy development and the feasibility of the application of certain environmental measures are related with the assessment of the impact of energy sector on the environment, both under existing conditions and in prospect. An information and analytical system is developing which include an assessment of the feasibility of applying the best available techniques for a founded choice of environmental measures in the energy sector. The choice of the best technology is based on the determination of the amount and ingredient composition of emissions of pollutants into the atmosphere from energy objects.
\end{abstract}

Keywords: Decreasing air pollution, energy objects, methodology, elements of the environment, coordinated solution.

\section{Introduction}

Energy sector in this study is seen as a critical infrastructure. First of all, it is a complicated many industry branch and multi-objects system which including the extraction of fuel and energy resources (FER), the production of net products - electric and thermal energy and its transfer to the end consumer. The energy sector is being a foundation for the economic activity from the development of which industrial production and the getting of other products depend. In general, this branch of economy contributes to the rise of welfare and, ultimately, ensures the quality of population life. At present, providing more environmentally friendly energy supply to consumers is becoming ever more urgent. In this connection, environmental protection technologies play a significant role in terms of environmental safety. Such technologies in the context of research are an important link in critical infrastructure, affecting on the development of energy sector in general.

\section{Methodological approaches}

Functioning and development of energy sector affects on all elements of the environment: atmosphere, water objects, soils, flora and fauna, human. This influence depends both on the specifics of production and on the characteristics of the territory where this production is carried out.

\subsection{The specific of energy sector impact on the environment}

The energy sector includes coal, oil and gas extraction, electricity-, heat production objects (power plants and boiler houses), and also transport systems of energy resources.

The specific of energy sector impact is determined by the volume and composition of pollutants entering in each element of the environment

The extraction of fuel and energy resources has the greatest impact on soils and water objects. Influence on soils is associated with disruption of landscapes and the formation of a significant amount of waste. Mostly it is a waste of coal mining the $\mathrm{V}$ class of hazard (practically non-hazardous), in a smaller amount drilling waste and oil sludge which has the III class of hazard (moderately hazardous) and waste from hydrocarbon production the IV class of hazard (low hazard). As a rule, in water objects during the extraction of fuel and energy resources a wastewater of various classes of danger are enter. 
And also the specific of energy sector impact on the environment varies on depend of the energy resource used for the production of electricity and heat.

Generating enterprises where the energy resource is water (hydroelectric power stations) or hydrocarbons (natural gas, fuel oil, diesel fuel) have a least impact. Significant impact is on the atmosphere, if solid fossil fuels (coal, various kinds of wood fuel) are used as an energy resource both in large sources of energy generation and small ones. Thus, when coal is burned solid particles, sulfur and nitrogen oxides of the third hazard class are arrive into the atmosphere.

Heated normatively clean water enters to the water objects from large thermal power plants. Combustion of solid fuel in small energy supplies (boilers) is not directly related to the formation of wastewater, there are only losses of the heat carrier when transferring heat energy to the consumer.

When generating electric and heat energy by using solid fossil fuel ash-and-slag wastes of the IV class of danger are formed. Ash-and-slag wastes are placed on special ash storage, which require take away large areas.

At the same time, energy production and transmission of energy resources are associated with noise, heat and electromagnetic effects on the environment. In addition, when transporting energy resources, spills of oil products, leakage of hot water and so on are possible.

The specific of energy sector impact on the environment is characterized not only by the volume and composition of pollutants, but also by the technological conditions of emissions. So, the emission into the air basin from the high sources goes beyond the atmosphere ground layer and can enter into long-range transport. Whereas from energy objects with low emission, pollutants fall directly into the atmosphere ground layer where of human activity is carried out.

In general, it should be noted that the greatest impact of energy sector on the environment is associated with the atmosphere in where a significant amount of harmful substances receives and can spread over long distances and areas, washed out from the air onto the water surfaces and soils.

\subsection{Consideration of the regional features at assessing of the energy sector impact on the environment}

The characteristics of the territories (physical and climatic, natural-climatic, socio-economic) are formed regional features that determine, from the one hand, the level of economic development and comfort of the region, from the other, the permissible anthropogenic load [1].

So, the regional features of the eastern regions of Russia, first of all, this is harsh and prolonged cold period formed the high needs for thermal energy, and also the availability of significant volumes of coal was contributed to the development of energy generation by coal in these territories.

At present, coal is dominant in the structure of fuel consumption in the eastern regions (up to $50 \%$ ), while on average in Russia it is $16 \%$, Fig. 1[2].
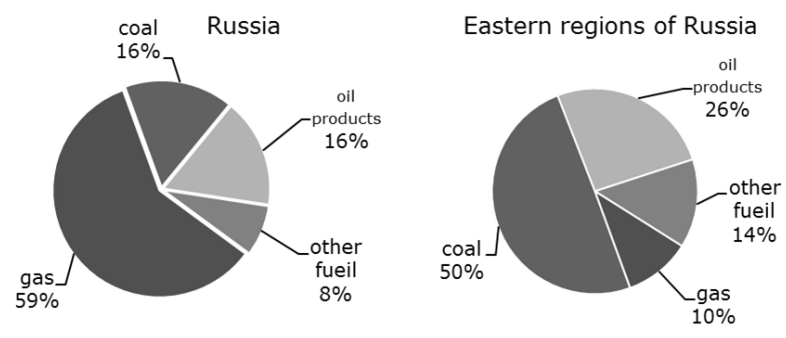

Fig. 1. The structure of fuel consumption in the eastern regions of Russia.

When assessing the impact of energy sector on the environment, the intensity of the impact is determined by regional characteristics, including the conditions of emissions and natural background, as well as the ability of the environment to restores.

In the Melentiev Energy Systems Institute of SB RAS a methodology for assessing the impact of energy sector on the environment is developed which include the estimation effectiveness of environmental protection measures, Fig.2.

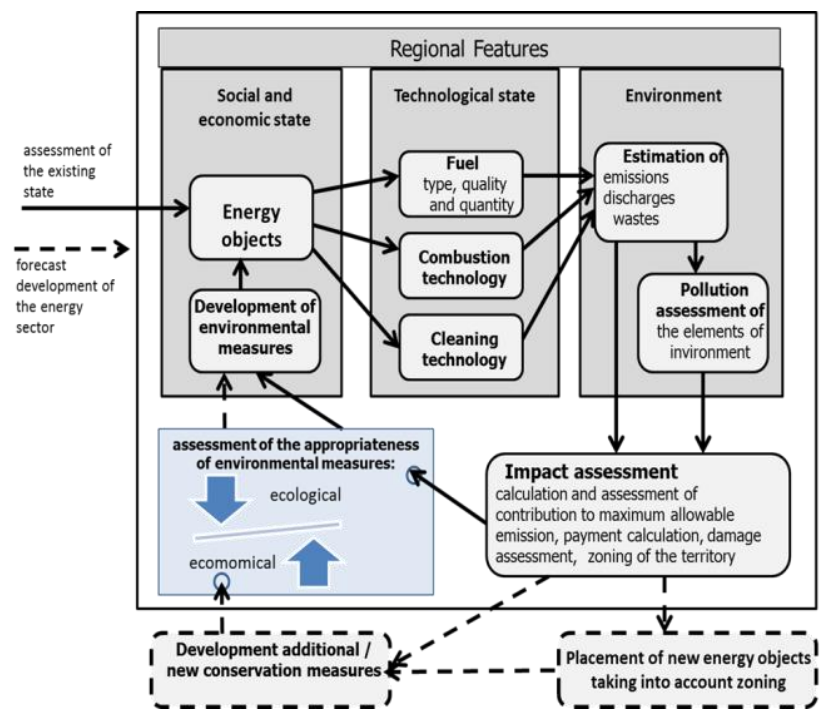

Fig. 2. Methodology for assessing the effectiveness of environmental protection measures in the energy sector. 
Currently, the proposed methodology is implemented in the form of a system of models for the calculations of emissions into the atmosphere, of the amount of ash and slag wastes, etc., under different scenarios of the energy sector development in the region.

These models allow carrying out an ecological assessment of the existing condition and efficiency of the measures already used.

For forecast development of energy sector and in the case of deterioration of existing state of the environment, new or additional environmental protection measures are being formed. For them the feasibility of application is estimated from both ecological and economic positions. In other words, an economic evaluation of the consequences from non-use of environmental protection measures is carried out.

In order to carry out an environmental assessment of energy development in each individual case, it is necessary to take into account the relevant indicators of the socio-economic state, technological and ecological characteristics of the region in question, which allows identifying specific environmental problems and developing or recommending specific environmental protection measures.

In each case, it is need to adapt the models for a particular region.

\subsection{Assessment of the impact of energy sector to the environment}

The main methods for assessing the impact of energy objects to the environment include officially approved methodical instructions for calculating pollutant emissions into the atmosphere by power plants and boilers with different capacities [3-6].

The calculation of all methods is based on mathematical dependencies with a detailed set of key indicators. In general, the amount of pollutant emissions depends on the qualitative composition of the fuel, its quantity (fuel consumption), combustion conditions in the boiler equipment and the operation of the purification equipment.

Numerous calculations showed that a change in one of the qualitative characteristics of fuels (ash content, sulfur and nitrogen content, calorific value, etc.) under the same combustion conditions and methods of cleaning may affect the final result (the amount of emission). Thus, there is a direct dependence of volume of emissions on the amount of burned fuel and the reverse one - from its quality characteristics (the better the fuel, the lower the emission).
In general, the scheme for calculating the amount of emissions is shown in Fig. 3. At the beginning the input and definition of initial information is carried out. Then the calculation of the emission volume is conduct directly on the basis of the methodical instructions, and next the results were presented in an illustrated form (graphs, diagrams) with possible recommendations.

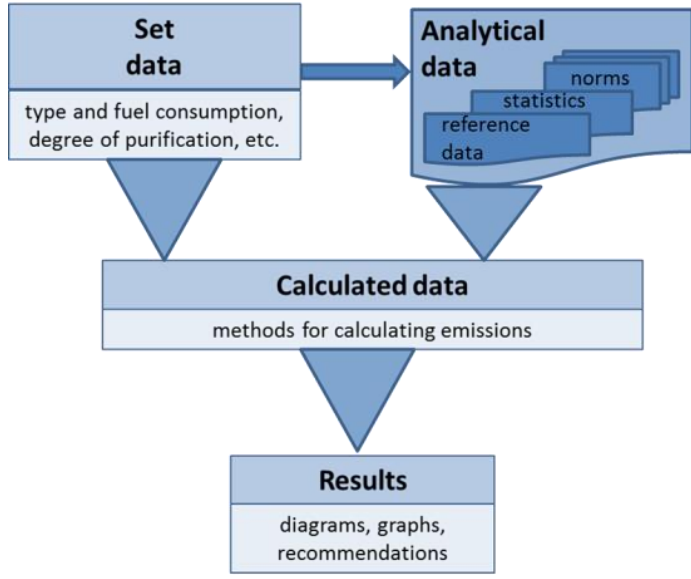

Fig. 3. Scheme of calculation of pollutant emissions.

It is often necessary to estimate the amount of emissions for a city, district or a whole region when detailed information is not available, so the itself calculation becomes cumbrous and in this occasion the detailed indicators are replaced by complex ones.

For an enlarged calculation, the assessment qualitative composition of the used fuel is made by expert, as the result an average values (weighted average ash content, sulfur and nitrogen content, calorific range) are choice. The volume of burned fuel is sets at heat power plant, in large and small boiler houses. In according to the methodical instructions for the calculation of the amount emissions, the characteristics of the fuel combustion conditions are set for example the share of fly ash, heat losses with chemical and mechanical underburning for chamber burning or combustion in layer and other indicators. In case of absence the information about treatment facilities, expert analysis is carried out in each specific case and the degree of cleaning of flue gases is determined (by the composition of the boiler equipment, according to statistical data on the trapping of pollutants, etc.).

As a result, adaptation of emission calculation models for the complex calculation is carried out, which allows to orientate in decision-making and recommend priority environmental protection measures. 


\section{The best available environmental protection techniques for the energy sector}

As noted above, energy generation by use coal has a significant effect on the atmosphere. Accordingly, the first-priority measures in the energy sector are the atmosphere-protection measures.

To reduce emissions into the atmosphere in the energy sector, there are a number of key directions:

- $\quad$ preliminary preparation of fuel before burning;

- technological measures to reduce the production of harmful admixtures in the process of fuel combustion (design changes, control of operation, use of fuel additives)

- flue gas cleaning from harmful admixtures by filters

- replacement of one fuel type with another, a more environmentally-friendly one;

- adoption of zero-waste technologies, through the involvement of pollutants into a new production process.

Currently, the choice of the nature protection measures is guided by the information and technical reference book (ITRB 22-2016) [7]. This reference book presents technologies and technological solutions aimed at reducing the emissions of pollutants into the atmosphere, the so-called best available techniques well -proven in the domestic market.

With the introduction of changes to the Federal Law "On Environmental Protection", the principles of the best available techniques have been developed. According that the possibilities for the transition to effective protection of the environment and the implementation of environmental standards are define, including energy enterprises [8].

The best available techniques for energy objects are only those techniques which have become widely used in Russian and foreign enterprises and have industrial introduction, the least impact on the environment and also positive the economic and operational efficiency.

It should be noted that the possibility of applying the best available techniques at the operating enterprises are connected with:

- the improvement of purification systems, and above all, with the automation of purification process;

- the implementation of energy-, resource-saving principles;

- modernization of technological processes;

- organization of a controlling system for energy resources consumption.

It is important to improve the skills of staff.

The introduction of environmental protection technologies at new energy objects are assume the preliminary inclusion of these technologies in the process as a constructive element with taking into account the decreasing of energy-, water consumption and the reduction of capital and operating costs.

Approaches for the choice of techniques for reducing emissions into the atmosphere are developed depending on the composition of pollutants. Based on the fact that the state reports and reports of energy enterprises only data of amount emissions are present of the main four components: solids particular, oxides of carbon, sulfur and nitrogen, so for choosing the technology or recommendations those harmful impurities are consider.

The technologies for reducing emissions of particulate matter have widespread in Russia. In boilers and large power plants, various apparatuses and devices operate with an efficiency of trapping particulate matter from 50 to $99.9 \%$. With regard to gas emissions, only single, test and pilot gas purification plants with different degrees of recovery are currently operating.

\section{Information-analytical system for assessing the feasibility of the environmental technologies in the energy sector}

An information and analytical system is being developed in connection with the large amount of information in calculating emissions and feasibility of the application of environmental protection technologies in the energy sector. The system includes a database with a list of available technologies and their characteristics (advantages and disadvantages), and an analytical system that makes is possible to detect the main factors that effect on assessing the technical feasibility of the environmental protection technology, and assess both the environmental efficiency and the economic, Fig. 4.

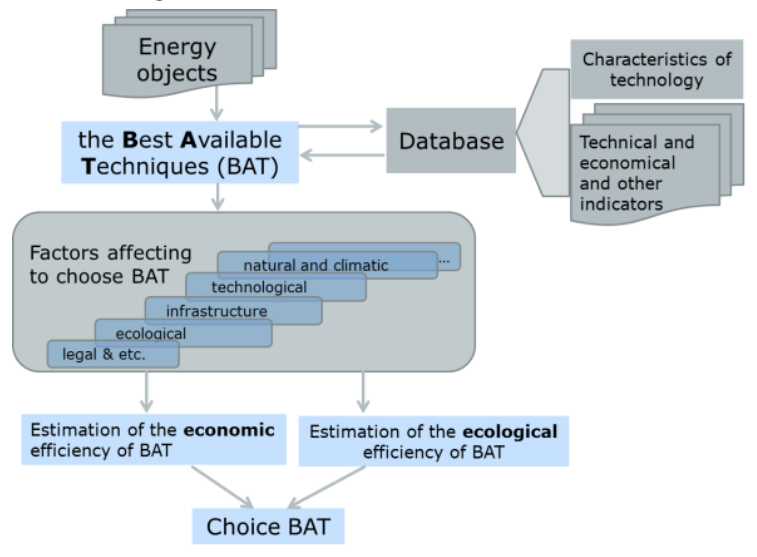

Fig. 4. Information-analytical system for a choice of environmental measures in the energy sector. 
The proposed information and analytical system can serve as a tool for supporting decision-making in analytical studies to assess both the current state of environmental technologies in the energy sector and the feasibility of introducing new environmental measures. One of the difficulties facing the information and analytical system to be developed is how to obtain a coordinated solution.

\section{Conclusion}

To ensure environmental safety in the functioning and development of energy sector, which considers as a complex and critical system, environmental protection technologies are the main measures. At present, the principles of the best available technologies have developed in Russia, which allotted to provide effective protection of all elements of the environment.

The predominance of coal in the fuel balance of both large and small sources generation of electric and thermal energy is a specific feature of the functioning and development of energy objects in the east of Russia. From an environmental standpoint, this feature determines the main types of impact on elements of the environment, to which a significant amount of emissions into the atmosphere should be attributed.

The estimation of feasibility of the application of environmental protection technologies in the energy sector, including the best available technologies for reducing emissions into the atmosphere, is carried out depending on the emission of pollutants inherent in the energy sector. And in this regard, one of the primary tasks is to calculate the amount of emissions, which allows determining the composition and identifying the main environmental problems. To assess the feasibility of the application of certain environmental protection measures it is necessary to compare the investment component and environmental effect from their implementation.

\section{Acknowledgements}

The research is conducted under support of the RFBR projects № 18-57-81001 and № 17-48-380002.

\section{References}

1. B. G. Saneev, E. P. Maysyuk, I. Yu. Nvanova, The regional features in the evaluating methods of impact of the energy complex on the environment, in Proceedings of the Russian Academy of Sciences. Power Engineering. 6 (2016), pp. 79-85.

2. B. G. Saneev, A. D. Sokolov, S. Yu. Muzichuk, E. P. Maysyuk, Fuel and energy complex of the Irkutsk oblast and its impact on the environment, in Book Actual problems of the science of the Baikal region, Issue 2.(The V. B. Sochava Institute of Geography, Irkutsk, 2017), pp. 175-180 (http://isc.irk.ru/ru/actual_problems)

3. Method of Determining Atmospheric Emissions of Pollutants Produced by Burning Fuel in Boilers Having Capacity of 30 ton of Steam per Hour or Less Than 20 GCal per Hour, (Firm Integral, St. Petersburg, 1999). (http://meganorm.ru/Index2/1/4294849/4294849657.htm)

4. Methodical letter of SRI Atmosphere from 17.05.2000 № 335 / 33-07 "About carrying out of calculations by a Method of Determining Atmospheric Emissions of Pollutants Produced by Burning Fuel in Boilers Having Capacity of 30 ton of Steam per Hour or Less Than 20 GCal per Hour", (Firm Integral, St. Petersburg, 2000).

5. Method for the Determination of Gross Atmospheric Emissions of Pollutants from Boilers of Thermal Power Stations, (All-Union Thermal Engineering Institute (VTI), Moscow, 1998).

6. A compendium of techniques for calculating air emissions of pollutants from various industries. (Hydrometizdat, Leningrad, 1986).

7. Cleaning of harmful (polluting) emissions into the atmosphere when manufacturing products (goods), carrying out work and rendering services at large-scale enterprises. Information and technical reference book on best available techniques (ITRBBAT 22-2016). (Federal Agency for Technical Regulations and Metrology: BAT Bureau, Moscow, 2016).

8. L. V. Makarevich, V. D. Kovalev, About the best available technologies in the field of electric power and energy saving, Energy Policy, 2 (2017) 19-26. 